\title{
The Influence of Resilience and Expressive Flexibility on Character Strengths and Virtues on Military Leadership in U.S. Military Cadets
}

\author{
Vasiliki Georgoulas-Sherry, PhD ${ }^{1 *}$
}

\begin{abstract}
Introduction: Character strengths and virtues are greatly revered in military leadership. However, there is no empirical work assessing the relationship of resilience and expressive flexibility, two essential psychological constructs crucial in nurturing mentally healthy individuals, also for successful officer development and military leadership.
\end{abstract}

Methods: Employing a cross-sectional design, this study recruited 107 participants (ages 18 to 22) from a private U.S. Military university. McGrath, Rashid, Park, and Peterson's and Peterson and Seligman's taxonomies of character strengths and virtues were measured. Self-reported resilience and expressive flexibility were additionally assessed.

Results: Results revealed McGrath et al.'s virtue of self-control and Peterson and Seligman's virtues of temperance, wisdom and knowledge, and humanity as the top ranked virtues for an effective military leader. In terms of character strengths, judgment ranked the highest, with perspective and fairness, second and third. Additional results showed a model suggesting that resilience and expressive flexibility explained $45.9 \%$ of variance suggesting that resilience and expressive flexibility significantly $(\mathrm{p}<.001)$ predicted leadership. Regression models that included honesty, social intelligence, and hope also offered significant predictive outcomes on leadership $(\mathrm{p}<.001)$. Furthermore, results revealed that expressive flexibility predicted the character strengths of creativity $(\mathrm{p}=.001)$, bravery $(\mathrm{p}=.045)$, love $(\mathrm{p}=.044)$, hope $(\mathrm{p}=.016)$, teamwork $(\mathrm{p}=.013)$, appreciation of beauty $(\mathrm{p}=.016)$, curiosity $(\mathrm{p}=.044)$, prudence $(\mathrm{p}=.034)$, love of learning $(\mathrm{p}=.020)$, zest $(\mathrm{p}=.017)$, humor $(\mathrm{p}=.018)$, and perspective $(\mathrm{p}=.003)$.

Conclusions: Understanding the relationships amongst these constructs will help in better cultivating protective mechanisms that safeguard from adversity, in encouraging wellness and health, and in supporting healthy human performance and development.
DOI: $10.18297 /$ jwellness/vol3/

iss $2 / 4$

Received Date: Feb 2, 2021

Accepted Date: June 29, 2021

Publication Date: July 16, 2021

Website: https://ir.library.louisville.edu/jwellness/

Recommended Citation:

Georgoulas-Sherry, Vasiliki (2021)

"The Influence of Resilience and

Expressive Flexibility on Character

Strengths and Virtues on Military

Leadership in U.S. Military

Cadets," Journal of Wellness: Vol.

3 : Iss. 2, Article 4.

Affiliations: ${ }^{1}$ Teachers College at

Columbia University

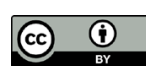

\section{INTRODUCTION}

To be a successful military leader one must be able to quickly acclimate and adapt to changing circumstances, persist and endure with determination regardless of failure, and adapt quickly from challenging environments and situations. Performing these missions and tasks, an effective military leader must have sound character [1-3]. In particular, individuals must be fearless in their convictions, honest in their behaviors and thoughts, and dependable in their actions. A sound character consists of a variety of applicable character strengths and virtues $[2,3]$. Character strengths are psychological features that depict virtues, and subsequently, are not independent systems of conduct and performance [4]. Virtues are defined as "predispositions toward moral excellence as means of solving the important tasks necessary for survival and advancement of the species" [5(p6)]. Understanding character strengths and virtues

${ }^{*}$ Correspondence To: Vasiliki Georgoulas-Sherry

Email: vg2346@tc.columbia.edu is important in creating and developing a successful leader, notably paramilitary and military contexts. In Values in Action (VIA) Inventory of Strengths, Peterson and Seligman [2] categorize 24 different character strengths into their six-virtue model. The six virtues include: courage, humanity, justice, wisdom and knowledge, transcendence, and temperance. Through a hierarchical regression approach, McGrath et al. [1] recommended a three-virtue model (i.e., caring, inquisitiveness, and self-control) with 18 distinct character strengths. For this study, both taxonomies are assessed.

Character strengths and virtues are positively associated to altruistic actions, thoughts, and behaviors [2], wellness [6], and work and life satisfaction [4]. Further work has suggested that certain character strengths (e.g., kindness, hope, perspective, social intelligence and self-control) are protective mechanisms

Copyright: (c) 2021 The author(s). This is an open access article distributed under the terms of the Creative Commons Attribution 4.0 International License (CC BY 4.0 ), which permits unrestricted use, distribution, and reproduction in any medium, provided the original author and source are credited. 
against potential deleterious influences of trauma and adversity [4]. As the field of positive psychology continues to grow, the roles of character strengths and virtues are essential due to their role in supporting optimal human development, and subsequently, human performance [5]. Additionally, as character strengths and virtues continue to be revered in successful military leadership, U.S. and non-U.S. armed forces military doctrines and studies alike endorse the magnitude of character strengths and virtues [3, 7-8]. In 2006, using a United States Military Academy (USMA)'s cadet sample, Matthews et al [3]. reported the top ranked character strengths as hope, bravery, honesty, industry, and teamwork. In 2015, Boe et al [7] found that citizenship, self-regulation, bravery, social intelligence, open-mindedness, fairness, integrity, perspective, love of learning, leadership, persistence, and creativity were the highly rated character strengths with the Norwegian Military Academy (NMA)'s cadets.

While previous research shows the value of character strengths and virtues, no current research evaluates the relationship of resilience and expressive flexibility on character strengths and virtues. Resilience is operationalized in the context of an individual's ability to bounce back to normal functioning following substantial trauma and adversity [9]. Expressive flexibility is the capacity to enhance (i.e., improved and heightened) and suppress (i.e., reduced and repressed) emotions [10]. As these two constructs are critical in predicting and shaping human performance, the associations amongst character strengths and virtues can influence office development and military leadership [11]. By understanding these relationships, effective military leadership development can be better theorized [8]. Furthermore, resilience and expressive flexibility have been essential constructs in effective psychological health, wellness, and adjustment [10, 12-13] First, resilient individuals are more likely to "bounce back" from a negative experience with "competent functioning" than non-resilient individuals [9]. Second, individuals who are high in expressive flexibility can enhance (i.e., heightened and improved) and suppress (i.e., repressed and reduced) emotional expression [13]. Resilience and expressive flexibility are critical in the effective acclimation and adaption to adverse contexts and situations.

Resilience and expressive flexibility have been associated with effective military performance. This includes the capability to foster positive mental health development following substantial stress [9] and the ability to reduce and stabilize military operational trauma [14-15]. Therefore, it can be theorized that if resilience and expressive flexibility are necessary for effective officer development and military leadership, then these positive psychology constructs could also be linked to character strengths and virtues that are valued in effective military leadership. Importantly, while this study assesses a military population, research has shown that a number of populations (e.g., healthcare professionals, civilian emergency personnel) suffer from similar demands (e.g., need to maintain healthy human performance, capacity to cultivate positive mental health development following adversity, persevering regardless of failure) allowing for potential applicability in a variety of contexts.

\section{Current Study}

While character strengths and virtues are highly revered in effective leadership [3, 7-8], there is scarce empirical work assessing character strengths and virtues that best produce an effective leader. Furthermore, to the author's knowledge, there are no prior studies that investigate the relationship of resilience and expressive flexibility in relation to character strengths and virtues. Specifically, this project aims to ascertain the relationship of resilience and expressive flexibility on character strengths and virtues for effective military leadership.

\section{METHODS}

The three aims for this research endeavor are as followed:

- Aim 1: As characters strengths and virtues have been revered as crucial constructs in effective leadership, the first aim assesses which character strengths and virtues best support a successful leader using both McGrath et al.'s and Peterson and Seligman's taxonomies.

- Aim 2: As both resilience and expressive flexibility have shown to be crucial in facilitating and promoting effective military leadership development and predicting and shaping human performance, the second aim is to assess the relationship of resilience and expressive flexibility on character strengths and virtues for effective military leadership.

- Aim 3: As character strengths, virtues, resilience, and expressive flexibility have shown to be critical mechanisms in human development and have been recognized as significant predictors in facilitating wellness and mental health and in successful leadership, the third aim will evaluate these associations on military leadership.

\section{Participants}

Employing 107 participants from a private US Military university which houses all military branches (i.e., Army, Navy, Marines, Air Force, and Coast Guard), this study included individuals who identified as either female $(34 \%)$ or male $(66 \%)$, between the ages of 18 to 22 . Participants were either freshmen (40\%) or sophomores (34\%); this was consistent to their age with participants either being 19 years old (38\%) or 18 years old (34\%). As Corps of Cadets members, more than half $(54.2 \%)$ reported that they were a leader in their cadet group.

\section{Materials}

The first (self-report) scale administered was the 32-item Resilience Scale for Adults (RSA). This scale assesses resilience through measuring intrapersonal and interpersonal protective factors linked to resilience [16]. The second (self-report) scale administered was the 16-item The Flexible Regulation of Emotional Expression (FREE) scale. This scale assesses the capacity to suppress and enhance emotions across a variety of contexts. Character strengths and virtues were measured using McGrath et al.'s and Peterson and Seligman's taxonomies. 


\section{Procedure}

The study was conducted with approval from Teacher's College, Columbia University's Institutional Review Board (IRB) (17-186). Word-of-mouth recruitment (i.e., professors offered extra credit for participation) was utilized. Participants were provided with a Qualitrics link to complete the two scales, the RSA and FREE scale. In addition, participants ranked in level of importance the character strengths and virtues that they thought to be essential to become a successful military leader.

\section{RESULTS}

A cross-sectional experimental design was employed to assess the relationship of resilience and expressive flexibility on character strengths and virtues for effective military leadership. $\mathrm{G}^{\star}$ Power 3.1.9.2 supported a sample size of 108 participants for medium-sized effects (Cohen's $=.32$ ) with acceptable statistical power [17]. Participants self-reported as moderately flexible in regulation of emotional expression (e.g., expressive flexibility) $(\mathrm{M}=11.99, \mathrm{SD}=1.77)$ and moderately resilient $(\mathrm{M}=5.54, \mathrm{SD}$ $=.93)$. Males were significantly more likely to be resilient $(\mathrm{M}=$ $5.67, \mathrm{SD}=0.79)$ than females $(\mathrm{M}=5.29, \mathrm{SD}=1.13)(\mathrm{t}(105)=$ $2.01, \mathrm{p}=.047)$; differences were not found between expressive flexibility and gender $(\mathrm{t}(105)=-0.45, \mathrm{p}=.66$, NS). No age differences were found in resilience $(\mathrm{F}(4,102)=2.10, \mathrm{p}=.08$, NS) or expressive flexibility $(\mathrm{F}(4,102)=1.07, \mathrm{p}=.37$, NS) Additionally, a Pearson product-moment correlation coefficient was used to assess the relationship between resilience and expressive flexibility $(\mathrm{r}=.37, \mathrm{p}<.001)$, suggested these two traits correlated to one another. Bivariate correlations were used to evaluate the magnitude and direction of statistical relationship amongst resilience, expressive flexibility, character strengths and virtues on cadet leadership (i.e., binary variable denoted as self-reported leadership role) (see Table 1 in Appendix A).

\section{Aim 1}

To evaluate the value of character strengths and virtues of an effective leader, both McGrath et al.'s and Peterson and Seligman's taxonomies of character strengths and virtues were used. An overview of participants' character strengths and virtues rankings are found on Table 2 . Results showed that participants ranked McGrath et al.'s virtue of self-control as most important for effective military leader (45.8\%), followed by caring $(42.1 \%)$ and then, inquisitiveness (12.1\%). In terms of Peterson and Seligman's taxonomy of virtues, wisdom and knowledge was ranked first (37.4\%), humanity was ranked second (37.2\%), and temperance was ranked third (14.0\%). Results further showed that the top Peterson and Seligman's character strengths were: (1) judgement (18.7\%), (2) perspective (15.9\%), and (3) fairness $(13.1 \%)$.

\section{$\operatorname{Aim} 2$}

To assess the relationship of resilience and expressive flexibility on character strengths and virtues for effective military leadership, ordinal logistic regression (ORL) analyses were conducted due to the continuous nature of resilience and expressive flexibility (i.e., independent variables) and ranked character strengths and virtues (i.e., dependent variables).
Table 2: Mean Values, Standard Deviations, and Ranks for Character Strengths and Virtues

\begin{tabular}{lccc}
\hline & M & SD & Rank (\#) \\
\hline Peterson and Seligman's (2004) Character Strengths & & \\
Judgment & 7.82 & 4.54 & 1 \\
Perspective & 7.36 & 5.39 & 2 \\
Fairness & 7.66 & 4.67 & 3 \\
Kindness & 7.05 & 3.76 & 4 \\
Bravery & 7.27 & 4.65 & 5 \\
Humility & 8.61 & 3.19 & 6 \\
Perseverance & 7.51 & 4.03 & 7 \\
Social Intelligence & 7.80 & 3.67 & 8 \\
Leadership & 7.26 & 4.24 & 9 \\
Forgiveness & 8.27 & 4.87 & 10 \\
Teamwork & 7.6 & 4.47 & 11 \\
Prudence & 8.21 & 4.32 & 12 \\
Honesty & 8.33 & 3.26 & 13 \\
Gratitude & 9.70 & 4.44 & 14 \\
Self-Regulation & 9.99 & 3.70 & 15 \\
Love of Learning & 18.32 & 2.19 & 16 \\
Spirituality & 18.97 & 2.44 & 17 \\
Hope & 19.89 & 2.28 & 18 \\
Humor & 18.21 & 2.03 & 19 \\
Creativity & 21.23 & 2.78 & 20 \\
Zest & 18.79 & 1.76 & 21 \\
Curiosity & 20.65 & 2.07 & 22 \\
Love & 22.12 & 1.90 & 23 \\
Appreciation of Beauty & 22.11 & 1.64 & 24 \\
\hline McGrath et al.'s (2010) Virtues & & & \\
Self-Control & 1.83 & 0.85 & 1 \\
Caring & 2.04 & 0.94 & 2 \\
Inquisitiveness & 2.13 & 0.60 & 3 \\
\hline Peterson and Seligman's (2004) Virtues & & & \\
Wisdom and Knowledge & 2.64 & 1.64 & 1 \\
Humanity & 2.39 & 1.34 & 3 \\
Temperance & 3.22 & 1.47 & 4 \\
Courage & 3.76 & 1.36 & 6 \\
Transcendence & 4.91 & 1.69 & \\
Justice & 4.06 & 1.37 & \\
& & & \\
\hline
\end{tabular}

Findings showed that resilience predicted the character strengths of curiosity $(\mathrm{OR}=38.40, \beta=3.65)\left(x^{2}(35)=54.43\right.$, $\mathrm{p}=.019)$, humility $(\mathrm{OR}=23.78, \beta=3.17)\left(x^{2}(35)=60.78, \mathrm{p}=\right.$ $.004)$, fairness $(\mathrm{OR}=11.62, \beta=3.33)\left(x^{2}(35)=59.66, \mathrm{p}=.006\right)$, appreciation of beauty $(\mathrm{OR}=23.69, \beta=3.17)\left(x^{2}(35)=51.23, \mathrm{p}\right.$ $=.038)$, hope $(\mathrm{OR}=34.06, \beta=3.53)\left(x^{2}(35)=64.94, \mathrm{p}=.002\right)$, and social intelligence $(\mathrm{OR}=43.08, \beta=3.76)\left(x^{2}(35)=51.02\right.$, $\mathrm{p}=.039)$. Nagelkerke modifications showed resilience's proportion of variation in the character strengths of curiosity $\left(\mathrm{R}^{2}\right.$ $=41.2 \%)$, humility $\left(\mathrm{R}^{2}=43.8 \%\right)$, fairness $\left(\mathrm{R}^{2}=43.1 \%\right)$, appreciation of beauty $\left(R^{2}=40.6 \%\right)$, hope $\left(R^{2}=46.5 \%\right)$, and social intelligence $\left(\mathrm{R}^{2}=38.4 \%\right)$. Furthermore, results revealed that expressive flexibility predicted the character strengths of creativity $(\mathrm{OR}=21.56, \beta=4.38)\left(x^{2}(37)=69.71, \mathrm{p}=.001\right)$, bravery $(\mathrm{OR}=17.17, \beta=1.79)\left(x^{2}(37)=52.79, \mathrm{p}=.045\right)$, love $(\mathrm{OR}=$ $14.90, \beta=1.83)\left(x^{2}(37)=52.86, \mathrm{p}=.044\right)$, hope $(\mathrm{OR}=15.40, \beta$ $=1.84)\left(x^{2}(37)=57.77, \mathrm{p}=.016\right)$, teamwork $(\mathrm{OR}=22.83, \beta=$ 1.05) $\left(x^{2}(37)=58.74, \mathrm{p}=.013\right)$, appreciation of beauty $(\mathrm{OR}=$ $19.42, \beta=1.86)\left(x^{2}(37)=57.74, \mathrm{p}=.016\right)$, curiosity $(\mathrm{OR}=17.80$, $\beta=1.85)\left(x^{2}(37)=52.85, \mathrm{p}=.044\right)$, prudence $(\mathrm{OR}=23.03, \beta=$ $3.67)\left(x^{2}(37)=54.16, \mathrm{p}=.034\right)$, love of learning $(\mathrm{OR}=19.81, \beta$ $=2.89)\left(x^{2}(37)=57.78, \mathrm{p}=.020\right)$, zest $(\mathrm{OR}=18.12, \beta=1.84)\left(x^{2}\right.$ $(37)=57.47, \mathrm{p}=.017)$, humor $(\mathrm{OR}=14.66, \beta=2.32)\left(x^{2}(37)=\right.$ $57.35, \mathrm{p}=.018)$, and perspective $(\mathrm{OR}=14.05, \beta=1.75)\left(x^{2}(37)\right.$ $=64.85, \mathrm{p}=.003)$. Nagelkerke modifications showed expressive flexibility's proportion of variation among the character strengths of creativity $\left(\mathrm{R}^{2}=49.1 \%\right)$, bravery $\left(\mathrm{R}^{2}=39.3 \%\right)$, love $\left(\mathrm{R}^{2}=41.5 \%\right)$, hope $\left(\mathrm{R}^{2}=42.6 \%\right)$, teamwork $\left(\mathrm{R}^{2}=42.7 \%\right)$, appreciation of beauty $\left(\mathrm{R}^{2}=44.4 \%\right)$, curiosity $\left(\mathrm{R}^{2}=40.2 \%\right)$, prudence $\left(\mathrm{R}^{2}=40.2 \%\right)$, love of learning $\left(\mathrm{R}^{2}=42.2 \%\right)$, zest $\left(\mathrm{R}^{2}=42.6 \%\right)$, 
humor $\left(R^{2}=43.1 \%\right)$, and perspective $\left(R^{2}=46.0 \%\right)$.

More so, results showed that resilience predicted McGrath et al.'s virtues of caring $(\mathrm{OR}=23.27, \beta=3.15)\left(x^{2}(35)=67.54, \mathrm{p}<\right.$ $.001)$ and self-control $(\mathrm{OR}=23.83, \beta=3.17)\left(x^{2}(35)=73.38, \mathrm{p}\right.$ $<.001)$ and Peterson and Seligman's virtues of courage (OR = $26.21, \beta=3.27)\left(x^{2}(35)=51.72, \mathrm{p}=.034\right)$ and temperance (OR $=30.75, \beta=3.43)\left(x^{2}(35)=55.68, \mathrm{p}=.015\right)$. Nagelkerke modifications revealed resilience's proportion of variation amongst McGrath et al.'s virtues of caring $\left(\mathrm{R}^{2}=54.5 \%\right)$ and self-control $\left(\mathrm{R}^{2}=56.3 \%\right)$ and Peterson and Seligman's virtues of courage $\left(R^{2}=39.8 \%\right)$ and temperance $\left(R^{2}=41.9 \%\right)$. Findings revealed that expressive flexibility predicted Peterson and Seligman's [2] virtue of wisdom and knowledge $(\mathrm{OR}=18.78, \beta=1.79)\left(x^{2}(37)\right.$ $=56.54, \mathrm{p}=.021)$, humanity $(\mathrm{OR}=12.91, \beta=2.38)\left(x^{2}(37)=\right.$ $209.90, \mathrm{p}<.001)$, justice $(\mathrm{OR}=10.41, \beta=1.87)\left(x^{2}(37)=58.85\right.$, $\mathrm{p}=.024)$, and temperance $(\mathrm{OR}=13.47, \beta=1.82)\left(x^{2}(37)=\right.$ $60.28, \mathrm{p}=.009)$. Nagelkerke modifications showed expressive flexibility's proportion of variation amongst Peterson and Seligman's virtue of wisdom and knowledge $\left(\mathrm{R}^{2}=42.9 \%\right)$, humanity $\left(R^{2}=90.9 \%\right)$, temperance $\left(R^{2}=44.5 \%\right)$, and justice $\left(R^{2}=42.5 \%\right)$.

\section{Aim 3}

Character strengths, virtues, resilience, and expressive flexibility have demonstrated to be vital mechanisms for optimal human development and have been assessed as considerable predictors in successful leadership behavior. First, to assess this aim, several regression analyses were computed to evaluate if character strengths, virtues, resilience, and expressive flexibility significantly predicted leadership. Second, an area under the curve (AUC) from receiver operating characteristic (ROC) analyses was completed. Lastly, odds ratios from logistic regression analyses were conducted [18].

Model 1 (i.e., the first model) consisted of resilience and expressive flexibility, with no character strengths or virtues; findings from this model revealed that resilience and expressive flexibility predicted leadership $(\mathrm{F}(2,104)=44.13, \mathrm{p}<.001)$, suggesting that resilience and expressive flexibility accounted for $45.9 \%$ of total variability in leadership (see Table 3). This study utilized guidance from Rice and Harris [18] to evaluate AUC (i.e., $.56=$ small, $.64=$ moderate, $.71=$ large), resilience revealed a high AUC value (.998), and expressive flexibility revealed a low AUC value (.614). When McGrath et al.'s virtues were added to the regression models, while all models were statistically significant, no better model was exhibited. In terms of Peterson and Seligman's virtues were included to the regression models, while all models were statistically significant, no better model was presented. For example, Model 2, consisting of resilience, expressive flexibility, and Peterson and Seligman's virtue of courage was statistically significant in predicting leadership $(\mathrm{F}(3,106)=32.80, \mathrm{p}<.001)$, suggesting resilience, expressive flexibility, and Peterson and Seligman's virtue of courage accounted for $48.9 \%$ of total variability in leadership. Significant main effects of resilience $(\mathrm{t}(1)=-9.37, \mathrm{p}<.001)$ and courage $(\mathrm{t}$ $(1)=2.44, p=.016)$ were statistically significant while expressive flexibility did not exhibit significance, $(\mathrm{t}(1)=0.26, \mathrm{p}=0.80$, NS) (see Table 3). Courage revealed small AUC values of .464. When adding Peterson and Seligman's virtue to justice to Model 2 (i.e., Model 3 - resilience, expressive flexibility, and Peterson and Seligman's virtue of courage and justice), Model 3 was statistically significant in predicting leadership $(\mathrm{F}(3,106)=25.71$, $\mathrm{p}<.001$ ), suggesting resilience, expressive flexibility, and Peterson and Seligman's virtues of courage and justice accounted for $50.2 \%$ of total variability in leadership.

Table 3: Model Predictions for Leadership

\begin{tabular}{|c|c|c|c|c|c|c|c|c|}
\hline \multirow[b]{2}{*}{ Model } & \multirow[b]{2}{*}{ Predictor } & \multicolumn{2}{|c|}{$\begin{array}{l}\text { Unstandardized } \\
\text { coefficients }\end{array}$} & \multicolumn{2}{|c|}{$\begin{array}{c}\text { Standardized } \\
\text { coefficients }\end{array}$} & \multirow[b]{2}{*}{$\mathrm{R}^{2}$} & \multirow[b]{2}{*}{$\mathrm{F}$} & \multirow[b]{2}{*}{$\mathrm{P}$} \\
\hline & & B & SE & b & $p$ & & & \\
\hline \multirow[t]{3}{*}{1} & & & & & & 0.46 & 44.13 & $<.001^{* * * *}$ \\
\hline & Resilience & -0.373 & 0.042 & -0.695 & $<.001^{* * *}$ & & & \\
\hline & $\begin{array}{l}\text { Expressive } \\
\text { Flexibility }\end{array}$ & 0.015 & 0.022 & 0.053 & 0.50 & & & \\
\hline \multirow[t]{4}{*}{2} & & & & & & 0.49 & 32.80 & $<.001^{* * *}$ \\
\hline & $\begin{array}{l}\text { Resilience } \\
\text { Expressive }\end{array}$ & -0.384 & 0.041 & -0.714 & $.001^{* * *}$ & & & \\
\hline & Flexibility & 0.006 & 0.022 & 0.020 & 0.796 & & & \\
\hline & Courage & 0.065 & 0.027 & 0.117 & $0.016^{* *}$ & & & \\
\hline \multirow[t]{6}{*}{3} & & & & & & 0.50 & 25.71 & $<.001^{* * * *}$ \\
\hline & Resilience & -0.385 & 0.041 & -0.717 & $<.001^{* * *}$ & & & \\
\hline & Expressive & & & & & & & \\
\hline & Flexibility & 0.002 & 0.022 & 0.005 & 0.945 & & & \\
\hline & Courage & 0.081 & 0.028 & 0.220 & $0.005^{* *}$ & & & \\
\hline & Justice & 0.045 & 0.027 & 0.123 & 0.10 & & & \\
\hline \multirow[t]{5}{*}{4} & & & & & & 0.48 & 31.22 & $<.001^{* * *}$ \\
\hline & Resilience & -0.385 & 0.042 & -0.717 & $.001^{* * *}$ & & & \\
\hline & Expressive & & & & & & & \\
\hline & Flexibility & 0.019 & 0.022 & 0.068 & 0.378 & & & \\
\hline & Honesty & -0.020 & 0.011 & -0.133 & 0.069 & & & \\
\hline \multirow[t]{8}{*}{5} & & & & & & 0.49 & 19.47 & $<.001^{* * * *}$ \\
\hline & Resilience & -0.384 & 0.042 & -0.714 & $.001 * * *$ & & & \\
\hline & Expressive & & & & & & & \\
\hline & Flexibility & 0.014 & 0.022 & 0.050 & 0.526 & & & \\
\hline & Honesty & -0.016 & 0.012 & -0.105 & 0.181 & & & \\
\hline & Hope & -0.022 & 0.016 & -0.098 & 0.183 & & & \\
\hline & Social & & & & & & & \\
\hline & Intelligence & 0.009 & 0.011 & 0.063 & 0.430 & & & \\
\hline
\end{tabular}

When Peterson and Seligman's character strengths were included in the regression models, all models were significant. Model 4, consisting of resilience, expressive flexibility, and Peterson and Seligman's character strengths of honesty was statistically significant in predicting leadership $(\mathrm{F}(3,106)=31.22$, $\mathrm{p}<.001$ ), suggesting resilience, expressive flexibility, and Peterson and Seligman's character strength of honesty accounted for $47.6 \%$ of total variability in leadership. Significant main effect of resilience $(t)=-9.24, p<.001)$ was present while expressive flexibility and honesty did not exhibit significance, $(\mathrm{t}(1)=$ $0.89, \mathrm{p}=0.38, \mathrm{NS})$ or $(\mathrm{t}(1)=-1.84, \mathrm{p}=0.069, \mathrm{NS})$, respectively (see Table 3). Honesty revealed small AUC values of 0.525 . When adding Peterson and Seligman's character strengths of hope and social intelligence to Model 4, Model 5 was statistically significant in predicting leadership $(\mathrm{F}(5,106)=19.47, \mathrm{p}<.001)$, suggesting resilience, expressive flexibility, and Peterson and Seligman's character strengths of honesty, social intelligence, and hope accounted for $49.1 \%$ of total variability in leadership. A significant main effect was only present in resilience $(t)=$ $-9.19, \mathrm{p}<.001)$, but no significant main effects were not present in expressive flexibility $(t(1)=0.64, p=0.53$, NS), hope ( $t$ (1) $-1.34, p=0.18, N S)$, honesty $(t(1)=-1.35, p=0.18$, NS), and social intelligence $(t(1)=0.79, p=0.43$, NS) (see Table 3). Honesty and social intelligence showed small AUC values of 0.525 and 0.485 , respectively 


\section{DISCUSSION}

Military doctrine describes the important role of character strengths and virtues in effective leadership. However, limited empirical work has reviewed the character strengths and virtues that best equip a successful leader [3,7]. Even more, no study has looked at the relationship of resilience and expressive flexibility on character strengths and virtues. This study serves as one of its kind in scientifically and systematically analyzing the impact of resilience, expressive flexibility, character strengths, and virtues on military leadership.

While each character strength and virtue is critical in effective leadership, as this study and previous work have shown, there appears to be lesser character strengths and virtues (in this study, curiosity, love, and appreciation of beauty, were ranked as the 22nd, 23rd, and 24th character strengths). For example, the United States Military Academy's cadets ranked courage, humanity, and justice as the top three Peterson and Seligman's virtues and honesty, industry, and hope as the top three Peterson and Seligman's [2] character strengths [3]. Findings from this study though, revealed that in terms of character strengths, the highest ranked character strengths were (1) judgment, (2) perspective, (3) fairness, (4) kindness, (5) bravery, and (6) humility. In terms of virtues, for McGrath et al.'s [1] taxonomy of virtues, the top virtue was self-control followed by caring and then, inquisitiveness. In terms of Peterson and Seligman's [2] taxonomy of virtues, wisdom and knowledge were classified as the highest ranked virtue, with humanity as second and temperance as third.

Findings from this study showed that resilience predicted Peterson and Seligman's taxonomy of character strengths of curiosity, humility, fairness, hope, appreciation of beauty, and social intelligence, McGrath et al.'s taxonomy of virtues of caring and self-control, and Peterson and Seligman's taxonomy of virtues of courage and temperance. As resilience encompasses the need to foster appropriate and healthy cognitive and mental wellness, such character strengths (e.g., humility, fairness, hope) and virtues (e.g., self-control, courage) are integral in the ability to stabilize after trauma. Furthermore, as findings revealed, expressive flexibility predicted Peterson and Seligman's taxonomy of character strengths of creativity, bravery, love, teamwork, zest, appreciation of beauty, curiosity, prudence, love of learning, humor, and perspective and Peterson and Seligman's taxonomy of virtues of justice, humanity, wisdom and knowledge, and temperance. As expressive flexibility consists of the ability to enhance and suppress emotional expression, such character strengths (e.g., curiosity, prudence, perspective) and virtues (e.g., humanity, temperance) are necessary in the capability to alternate between suppression and enhancement.

Finally, results showed that in terms of predictability of leadership, Model 3 (i.e., resilience, expressive flexibility, and Peterson and Seligman's virtues of courage and justice) and Model 5 (i.e., resilience, expressive flexibility, and Peterson and Seligman's character strengths of honesty, social intelligence, and hope), accounting for $50.2 \%$ and $49.1 \%$ of total variability in leadership, respectively. Interestingly, while the three Peterson and Seligman's character strengths of social intelligence, honesty, and hope, have shown to predict leadership, they ranked as eight, thirteenth, and eighteenth in effective leadership, respectively.

\section{Limitations}

Limitations could have affected the findings of this work. First, this research study employed a military college population, and findings might not be replicable or generalizable beyond military or college samples. For example, as the study utilized a sample from a private US Military university, this sample did not produce a comprehensive range of expressive flexibility or resilience levels; this could be in large part due to military academies' demanding curriculums not expected in other colleges. Second, in this research study, leadership was operationalized as a self-report measure (i.e., participants were asked if they were a leader within their cadet group); this narrow operationalization might have impacted findings as participants might not have had occasions to obtain leadership experience. Third, the recruiting method could also be deemed as a potential limitation as participants volunteered to partake in this study to obtain extra class credit in their psychology college courses; while this is a common practice in research studies, there are potential risks in interpreting results conducted within this framework. Fourth, while self-report scales are traditional tools utilized in research, participants might not have truthfully reported feelings of expressive flexibility or resilience. Fifth, due to the complexities surrounding the resilience's operationalization, numerous limitations surround resilience assessments such as the RSA; for example, Kalisch et al [19] argue that one could hardly report if they can bounce back from adverse event, therefore, making it difficult to truly assess resilience.

\section{Implications}

The necessity to better comprehend the influence of resilience and expressive flexibility on character strengths and virtues are infinite, as these constructs are integral in encouraging positively healthy individuals, in cultivating protective processes and mechanisms that safeguard individuals from adverse contexts, and in impacting healthy human development and performance [9]. As many military leaders are exposed to some form of violent or life-threatening encounter, it is critical that we further understand the constructs that shield from negative contexts and situations [14]. This endeavor discovered significant associations amongst these positive psychology constructs and further justifies the need to expand research in assessing influences of resilience and expressive flexibility on character strengths and virtues.

As character strengths and virtues are important in successful and effective leadership, comprehending top character strengths and virtues that contribute to effective military operations is essential. Particularly, educating future military leaders on the importance and relevancy of particular character strengths and virtues is vital. As this research reinforces the need to perform more studies to assess models of military leadership, more focus on resilience and expressive flexibility, in relation to predicting and shaping character strengths and virtues is essential.

By better understanding the theoretical framework and empirical relationship between these constructs, researchers 
are more likely to better recognize how to decrease the possible vulnerability to further stressors or measure the supplementary relationship on individual mental wellness. The more we learn about expressive flexibility and resilience, the more likely we are to incorporate salient concepts of expressive flexibility and resilience into relevant contextual environments for research in the fields of mental health, medicine, and science. Incorporating these concepts can facilitate a significant and necessary approach to thinking about adversity and challenge. According to Southwick et al. [20], instead of focusing efforts and energy to the continued negative outcomes and impacts of adversity and trauma, a need to focus on the positive consequences that emerge from such crisis are as important, if not, more integral, to investigate and further examine; this can also be said about the construct of expressive flexibility. This potential paradigm shift could help move the mental health, medicine and science fields away from the typical "purely deficit-based model," to instead, models that focus on individualized strengths and positive human functioning (like expressive flexibility and resilience), which centers on the prevention and deterrence of dysfunction, and the facilitating of strengths and positive constructs in understanding and attending to psychopathology [20, 21]. Such research could also help better understand the effects of the psychological construct of expressive flexibility and resilience and its influence on individual mental health and wellness.

Additionally, the existing interest to better comprehend positive psychology constructs have been valuable and integral during (and following) adverse contexts and situations, produced an increased need to recognize the interplays between resilience and expressive flexibility. This research study offers evidence of how resilience and expressive flexibility, two necessary constructs in promoting effective military development and leadership and predicting and shaping human performance, are linked to character strengths and virtues. This endeavor assessed which McGrath et al.'s and Peterson and Seligman's character strengths and virtues best characterizes a successful leader and investigated the relationship of resilience and expressive flexibility on character strengths and virtues for effective military leadership.

Lastly, while this study specifically looked at the influence of resilience and expressive flexibility on character strengths and virtues in U.S. military cadets, these findings can be generalized beyond this military population. Particularly, as explained in Bonanno et al. [9], many individuals will experience some sort of life-threatening or adverse encounter during their lifetime, and therefore, it can be assumed that these results could be applicable to other populations who are exposed to similar adversities. Most noteworthy, research has shown similar stressors and hardships among first responders, healthcare professionals, civilian emergency personnel, and disaster victims $[22,23]$. Research in this field could benefit these populations including police, healthcare, and fire and emergency departments with quantitative data on the influence of resilience and expressive flexibility, two constructs that serve in better cultivating protective mechanisms that safeguard from adversity, that encourage wellness and health, and that support healthy human performance and development.

\section{CONCLUSION}

While character strengths and virtues have been vital in successful officer development and military leadership as they serve as protective mechanisms against potential deleterious influences of trauma and adversity there is no current research that evaluates the relationship of resilience and expressive flexibility on character strengths and virtues, two essential positive psychological constructs crucial in nurturing mentally healthy individuals and reinforcing effective psychological health and adjustment. By better understanding the theoretical framework and empirical relationship amongst these constructs, the more likely we are to incorporate salient concepts of expressive flexibility and resilience into relevant contextual environments in behavioral and mental health, medicine, and science.

\section{REFERENCES}

1. McGrath RE, Rashid T, Park N, Peterson C. Is optimal functioning a distinct state? [Internet]. Humanist Psychol. 2010 May;38(2):159-69.

2. Peterson C, Seligman ME. Character strengths and virtues: A handbook and classification. Oxford, UK: Oxford University Press; 2004.

3. Matthews MD, Eid J, Kelly D, Bailey JK, Peterson C. Character strengths and virtues of developing military leaders: an international comparison [Internet]. Mil Psychol. 2009 Dec;18(sup1 S1):S57-68. Available from: https://www.researchgate.net/profile/Jarle_Eid/ publication/247503579_Character_Strengths_and_Virtues_of_Developing_Military_Leaders_An_International_Comparison/links/5fecd928299bf140885dedb6/ Character-Strengths-and-Virtues-of-Developing-Military-Leaders-An-International-Comparison.pdf

4. Park N, Peterson C, Seligman ME. Strengths of character and well-being [Internet]. J Soc Clin Psychol. 2004 Oct;23(5):603-19. Available from: http://citeseerx.ist.psu.edu/viewdoc/ download?doi=10.1.1.473.1295\&rep=rep1\&type $=$ pdf

5. Park N, Peterson C. Character strengths: research and practice [Internet]. J Coll Character. 2009 Apr;10(4):1-11.

6. Gillham J, Adams-Deutsch Z, Werner J, Reivich K, Coulter-Heindl V, Linkins M, et al. Character strengths predict subjective well-being during adolescence [Internet]. J Posit Psychol. 2011 Jan;6(1):31-44.

7. Boe O, Bang H, Nilsen FA. Experienced military officer's perception of important character strengths [Internet]. Procedia Soc Behav Sci. 2015 May;19(2):339-45.

8. Gayton SD, Kehoe EJ. A prospective study of character strengths as predictors of selection into the Australian army special force [Internet]. Mil Med. 2015 Feb;180(2):151-7.

9. Bonanno GA, Galea S, Bucciarelli A, Vlahov D. What predicts psychological resilience after disaster? The role of demographics, resources, and life stress [Internet]. J Consult Clin Psychol. 2007 Oct;75(5):671-82.

10. Burton CL, Bonanno GA. Measuring ability to enhance 
and suppress emotional expression: The Flexible Regulation of Emotional Expression (FREE) Scale [Internet]. Psychol Assess. 2016 Aug;28(8):929-41.

11. Maddi SR, Matthews MD, Kelly DR, Villarreal B, White $M$. The role of hardiness and grit in predicting performance and retention of USMA cadets [Internet]. Mil Psychol. 2012 Jan;24(1):19-28.

12. Aldao A, Sheppes G, Gross JJ. Emotion regulation flexibility [Internet]. Cognit Ther Res. 2015 Jun;39(3):263-78.

13. Chen S, Chen T, Bonanno GA. Expressive flexibility: enhancement and suppression abilities differentially predict life satisfaction and psychopathology symptoms. Pers Individ Dif. 2018 May;12(6):78-84.

14. Bartone PT. Resilience under military operational stress: can leaders influence hardiness? Mil Psychol [Internet]. 2006 Jan;18(sup1):S131-48 Available from: https://d1wqtxts1xzle7.cloudfront.net/39759891/ Resilience_Under_Military_Operational_St2015110625258-rg4imn.pdf?

15. Litz BT. Resilience in the aftermath of war trauma: A critical review and commentary. Interface Focus [Internet]. 2014 Oct;4(5):20140008. Available from: https://royalsociety publishing.org/doi/pdf/10.1098/ rsfs.2014.0008 https://doi.org/10.1098/rsfs.2014.0008.

16. Wagnild GM, Young HM. Development and psychometric evaluation of the Resilience Scale [Internet]. J Nurs Meas. 1993;1(2):165-78. Available from: https://cyberleninka.org/article/n/255719.pdf

17. Faul F, Erdfelder E, Buchner A, Lang AG. Statistical power analyses using $G^{*}$ Power 3.1: tests for correlation and regression analyses [Internet]. Behav Res Methods.
2009 Nov;41(4):1149-60.

18. Rice ME, Harris GT. Comparing effect sizes in follow-up studies: ROC Area, Cohen's d, and r [Internet]. Law Hum Behav. 2005 Oct;29(5):615-20.

19. Kalisch R, Baker DG, Basten U, Boks MP, Bonanno GA, Brummelman E, et al. The resilience framework as a strategy to combat stress-related disorders. Nat Hum Behav [Internet]. 2017 Nov;1(11):784-90. Available from: https://aspace.repository.cam.ac. uk/ bitstream/ handle/1810/270014/Manuscript_Kalisch_ R2-.pdf?sequence

20. Southwick SM, Bonanno GA, Masten AS, PanterBrick C, Yehuda R. Resilience definitions, theory, and challenges: interdisciplinary perspectives. Eur J Psychotraumatol. 2014 Oct;5(1):25338.

21. Ozer EJ, Best SR, Lipsey TL, Weiss DS. Predictors of posttraumatic stress disorder and symptoms in adults: a meta-analysis [Internet]. Psychol Bull. 2003 Jan;129(1):52-73.

22. Marklund LA, Graham AM, Morton PG, Hurst CG, Motola I, Robinson DW, et al. Collaboration between civilian and military healthcare professionals: a better way for planning, preparing, and responding to all hazard domestic events [Internet]. Prehosp Disaster Med. 2010 Sep-Oct;25(5):399-412.

23. Parry DA, Oeppen RS, Amin MS, Brennan PA. Sleep: its importance and the effects of deprivation on surgeons and other healthcare professionals. Br J Oral Maxillofac Surg. 2018 Oct;56(8):663-6. 


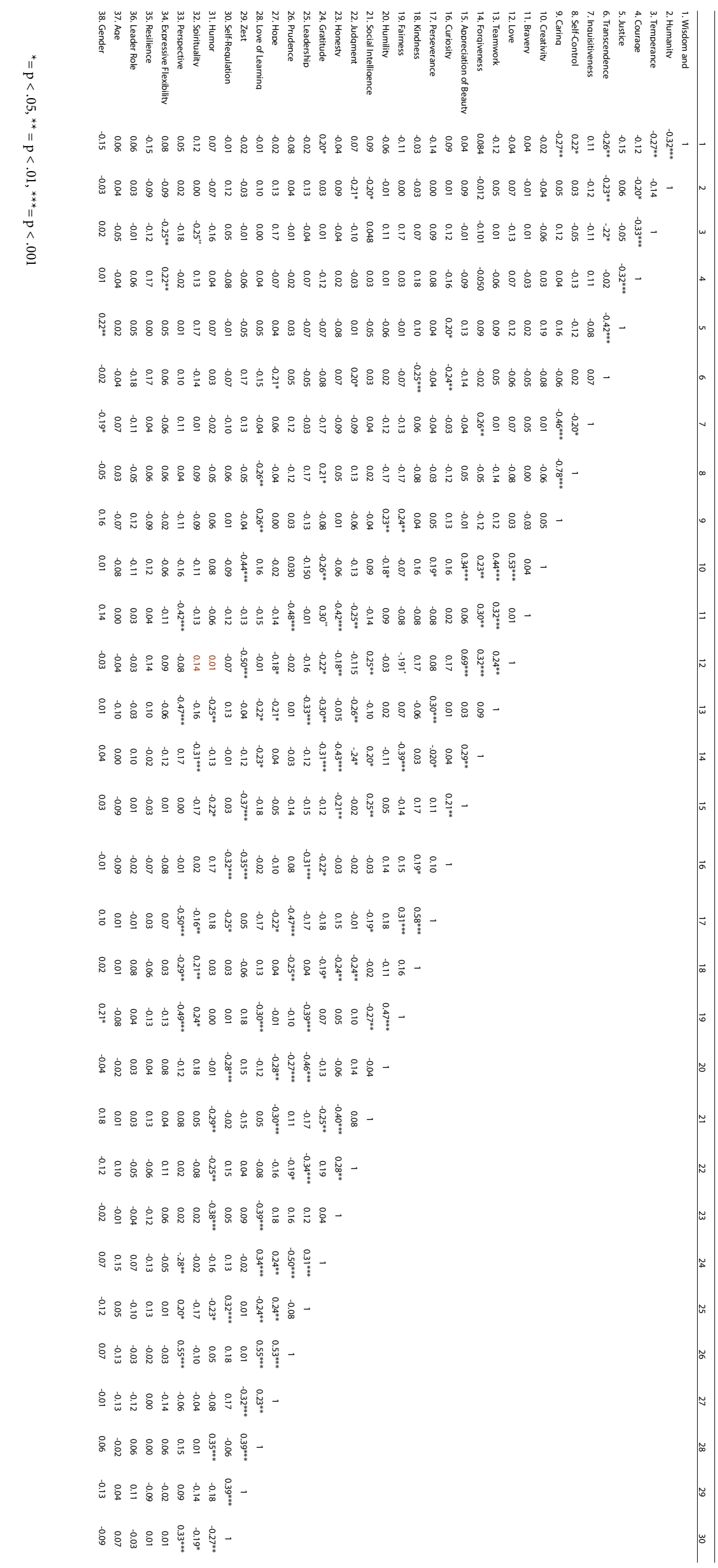

